\title{
Previsão de Cheias Sazonais para o Rio Negro Usando Redes Neurais Artificiais e Árvores de Decisão com Aprendizado Baseado em Comitê
}

\author{
Paula A. Marães, Marly G. F. Costa, Cícero F. F. Costa Filho \\ Centro de P\&D de Tecnologia Eletrônica e da Informação- CETELI \\ Universidade Federal do Amazonas - UFAM \\ CEP 69080-900, Manaus - AM - Brasil \\ paulamaraes14@gmail.com, \{mcosta, ccosta\}@ufam.edu.br
}

\begin{abstract}
Seasonal Black River floods affects mainly the riverside population. In this work we present a methodology to predict the flood peak, using two types of predictors: Artificial Neural Networks (ANN) and Decision trees. For the training of the predictors, the variables were selected using a modified characteristic scalar selection technique. The data used corresponds to the period 1951-2017. For improving the neural network generalization, the technique of regularization $L^{2}$ and early stop, associated with bootstrap were employed. For improving decision trees performance, committee-based learning method (boosting and bagging) was employed. Additionally, this work proposes classifying the river floods into four ranges of values. The efficiency of the predictors was evaluated using the Pearson correlation coefficient and accuracy in range classification. The predictions were obtained with 4,3,2 months and 1 month before the occurrence of river peak level. The best accuracy obtained in range classification was $85,07 \%$, for one month before the occurrence of peak level.
\end{abstract}

Resumo. A ocorrência das cheias sazonais dos rios afeta, principalmente, a população ribeirinha. Neste trabalho foram avaliados métodos capazes de prever o pico da cheia de rios, utilizando dois tipos de preditores: Redes Neurais Artificiais (RNA) e Árvores de Decisão. Para o treinamento dos preditores, as variáveis foram selecionadas através da técnica de seleção escalar de características modificada a partir de um conjunto de dados das cheias do Rio Negro relativo ao período de 1951-2017. Para melhorar a generalização das Redes Neurais foram utilizadas as técnicas de regularização $\mathrm{L}^{2}$ e parada antecipada, associadas a técnica bootstrap. Para melhorar a performance das árvores de decisão, métodos de aprendizado baseado em comitê (boosting e bagging), foram empregados. Esse artigo propõe ainda a classificação das cheias em faixas de valores. A eficiência dos preditores foi avaliada através do coeficiente de correlação de Pearson e da acurácia da classificação das cheias. As predições foram obtidas com 4,3,2 meses e 1 mês de antecedência em relação a ocorrência do pico da cheia. A melhor acurácia obtida na classificação em faixas foi de 85,07\% com um mês de antecedência com relação ao pico da cheia, para o preditor RNA (parada antecipada e bootstrap). 


\section{Introdução}

O Rio Negro é o maior afluente da margem esquerda do rio Amazonas, sendo o principal rio que passa às margens da cidade de Manaus, dando origem a uma rede de igarapés na cidade. As cheias sazonais do Rio Negro apresentam um longo tempo de percurso, cerca de sete/oito meses, iniciando em fevereiro. Seu máximo é alcançado entre os meses de junho e julho, coincidindo com o chamado verão Amazônico. Isso ocorre devido ao gigantesco tamanho da bacia hidrográfica e a pequena declividade dos leitos. A maior cheia já registrada do rio Negro, medida na cidade de Manaus, ocorreu em 2012 e atingiu a cota de 29,97 metros acima do nível do mar.

Esse fenômeno de subidas e baixas do rio atinge todos os rios da bacia Amazônica e impacta, principalmente, a população ribeirinha, que habita às margens dos rios, pois prejudica as atividades de pesca, agricultura e a criação de animais, assim como, compromete a própria habitação dessa população.

Em Manaus, o monitoramento do fenômeno de subidas e baixas do rio é feito pelo Serviço Geológico do Brasil em parceria com o Sistema de Proteção da Amazônia SIPAM. São emitidos boletins semanais que informam sobre a evolução das cheias às autoridades (defesa civil, corpo de bombeiros, governos estadual e municipal) e à população em geral [MMA, 2007].

Através de pesquisa em bases de dados bibliográficas identificou-se algumas publicações científicas que apresentam métodos e/ou sistemas de previsão de cheias, desenvolvidos com o intuito de obter informações antecipadas sobre essas ocorrências. Essas ferramentas podem ser utilizadas pelos órgãos públicos com o fim de minimizar os danos causados pelas cheias, através de uma previsão antecipada do pico das mesmas. Dentre esses trabalhos, destacam-se o de Córdoba-Machado et. al. [2016], de Schongart et. al. [2007] e o de Rodrigues et. al. [2015], que mostram a correlação das descargas da bacia Amazônica com padrões atmosféricos e oceânicos, como: a Temperatura da Superfície do Mar (do inglês, Sea Surface Temperature - SST) e o fenômeno climático El Niño South Oscillation (ENSO), e com as chuvas que ocorrem na região.

Nesse trabalho, pretendemos explorar novamente a predição da cheia do Rio Negro, procurando trazer para a área as seguintes contribuições: 1) comparar o desempenho de redes neurais com o método de aprendizado baseado em máquina de comitê, na previsão do pico da cheia do Rio Negro, através da utilização de índices climáticos e do nível do Rio Negro; 2) avaliar a previsão da cheia com 4, 3, 2 e 1 mês de antecedência; 3) propor uma classificação das cheias em faixas de valores/categorias e avaliar os erros dos preditores implementados, considerando a existência dessas faixas.

\section{Materiais e Métodos}

O diagrama em bloco da Figura 1 apresenta as etapas da metodologia proposta para realizar o treinamento dos preditores utilizados na previsão de cheias sazonais do Rio Negro, quais sejam: redes neurais artificiais e árvores de decisão.

No bloco a) da Figura 1, apresenta-se o conjunto de dados de entrada, composto por um conjunto inicial de variáveis: índices climáticos (ENSO e SOI) e os níveis do Rio Negro no período de 1951 - 2017. A partir do conjunto inicial são extraídas e selecionadas as nove melhores variáveis, segundo o método de seleção escalar de características, o qual foi modificado por Rodrigues et. al. [2015]. 
No bloco b) apresenta-se a metodologia de treinamento do comitê de árvores de decisão, que utilizam os métodos de aprendizado: bagging e boosting.

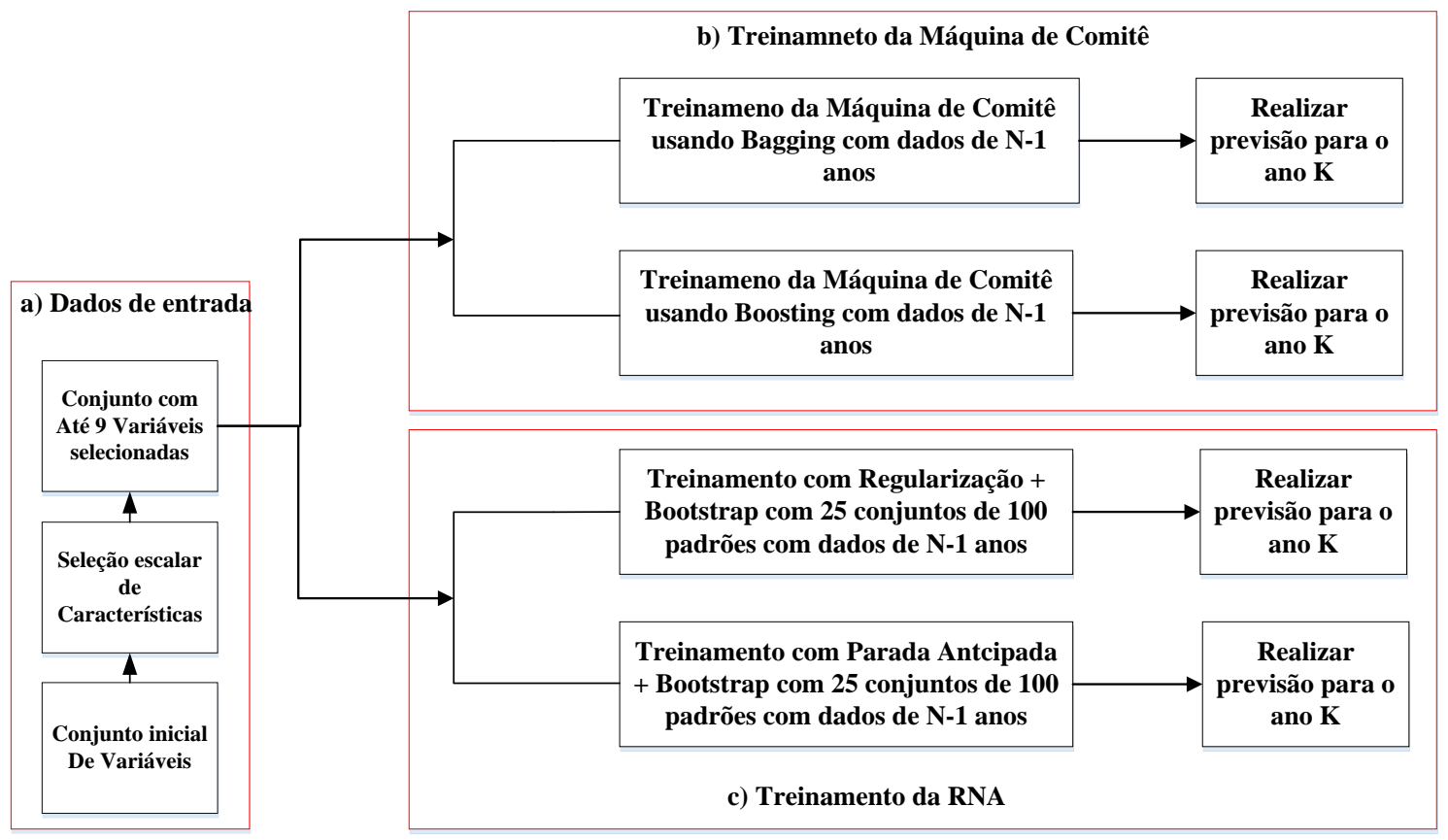

Figura 1. Metodologia utilizada para o treinamento dos preditores.

No bloco c) é apresentada a metodologia de treinamento usando RNA. Foram implementadas três arquiteturas de RNA, com diferentes números de neurônios nas camadas ocultas. No treinamento da RNA, o método bootstrap foi implementado com 25 conjuntos distintos.

\subsection{Conjunto de dados}

As variáveis utilizadas na entrada dos preditores foram índices climáticos e o nível do Rio Negro, obtidos num período de 67 anos $(\mathrm{N}=67)$, de 1951 à 2017. As cotas do Rio Negro foram coletadas no site da Agência Nacional de Águas - ANA [ANA, 2019] e na página oficial do Porto de Manaus [Porto de Manaus, 2018]. À semelhança dos trabalhos de Schongart et al. [2007] e Rodrigues et al. [2015] os índices climáticos utilizados foram: SST El niño ${ }_{1+2}$, SST El niño $o_{3}$, SST El niño ${ }_{3+4}$, SST El niño $o_{4}$ e o SOI [do inglês, South Oscillation Index]. Os valores dos índices climáticos foram coletados da página oficial do Climate Prediction Center [Climate Prediction Center, 2018]. Considerando que o pico das cheias ocorre no mês de junho tem-se que, quando a previsão é feita com 4 meses de antecedência, os valores dessas variáveis são extraídos dos meses de fevereiro, março, abril e maio. Quando a previsão é feita com 3 meses de antecedência, os valores dessas variáveis são extraídos dos meses de março, abril e maio. Quando a previsão é feita com 2 meses de antecedência, os valores dessas variáveis são extraídos dos meses de abril e maio. Quando a previsão é feita com 1 mês de antecedência, os valores dessas variáveis são extraídos do mês de maio.

\subsection{Metodologia de previsão}

Conforme já mencionado, os preditores utilizados neste trabalho são de dois tipos: redes neurais completamente conectadas e árvores de decisão. 
A metodologia leave-one-out [Sonka, et al., 2000] foi utilizada no treinamento dos preditores. Nessa metodologia, um determinado ano k, para o qual se deseja fazer a previsão, é removido do conjunto de $\mathrm{N}$ anos e o treinamento do preditor é efetuado com os dados de (N-1) anos. Depois de treinado, o preditor é utilizado para realizar a previsão do ano que foi removido. Variando-se o valor de k faz-se a previsão da cheia para todos os anos do conjunto de dados.

Para a seleção dos conjuntos de variáveis, utilizou-se o método de seleção escalar de características, modificado por Rodrigues et. al. [2015]. Dessa forma, seleciona-se as nove $(M=9)$ melhores características ou variáveis, procurando eliminar a redundância entre as mesmas. A Tabela 1 mostra o conjunto de variáveis utilizadas para o treinamento dos preditores em função da antecedência da previsão e ordenadas segundo o método de seleção de características aplicado.

Tabela 1. Conjunto de variáveis utilizadas para o treinamento dos preditores em função da antecedência da previsão e ordenadas pelo método de seleção de características modificado.

\begin{tabular}{cllll}
\hline \multirow{2}{*}{ Ordem } & \multicolumn{2}{c}{ Variáveis utilizadas para previsão segundo o período de antecedência em meses } \\
\cline { 2 - 5 } & \multicolumn{1}{c}{ 4 meses } & \multicolumn{1}{c}{ 3 meses } & \multicolumn{1}{c}{ 2 meses } & \multicolumn{1}{c}{ 1 mês } \\
\hline $1^{\text {o }}$ & Nível do rio fevereiro & Nível do rio março & Nível do rio abril & Nível do rio maio \\
$2^{\text {o }}$ & SOI em janeiro & Nível do rio janeiro & Nível do rio fevereiro & Nível do rio março \\
$3^{\text {o }}$ & SOI em setembro & SOI em novembro & SOI em janeiro & Nível do rio janeiro \\
$4^{\text {o }}$ & Nível do rio janeiro & Nível do rio fevereiro & Nível do rio março & Nível do rio abril \\
$5^{\text {o }}$ & SOI em novembro & SOI em janeiro & Nível do rio janeiro & Nível do rio fevereiro \\
$6^{\text {o }}$ & Soi em dezembro & El Niño 3+4 dezembro & El Niño 3+4 fevereiro & El Niño 3+4 janeiro \\
$7^{\text {o }}$ & El Niño 3+4 janeiro & SOI em setembro & SOI em novembro & SOI em janeiro \\
$8^{\text {o }}$ & El Niño 3+4 fevereiro & El Niño 3+4 janeiro & SOI em setembro & SOI em novembro \\
$9^{\circ}$ & El Niño 3+4 dezembro & El Niño 3+4 fevereiro & El Niño 3+4 janeiro & SOI em setembro \\
\hline
\end{tabular}

\subsection{Configuração e treinamento das redes neurais}

Foram utilizadas arquiteturas de redes neurais artificiais (RNA) com 4 camadas. Três arquiteturas distintas foram utilizadas. Elas diferem no número de neurônios das camadas escondidas: M-6-6-1, M-8-8-1 e M-10-10-1. O Método de otimização de LevenbergMarquardt foi empregado no treinamento. Na primeira e na segunda camada das redes, foi utilizada a função de ativação 'tansig'. Essa função se aproxima mais da função identidade e, segundo [Matsunaga, 2012], é considerada uma melhor opção para ativação das camadas escondidas das RNAs. Cada arquitetura foi treinada utilizando duas combinações de métodos para melhoria da generalização: regularização $\mathrm{L}^{2},+$ bootstrap e parada antecipada (Early Stop) + bootstrap.

\subsection{Método de regularização Bootstrap}

O método de regularização bootstrap foi implementado utilizando-se 25 treinamentos distintos. Em cada treinamento, um conjunto de dados diferente é utilizado e uma nova inicialização dos parâmetros da rede (pesos e polarizações) é efetuada. Depois de treinada, a rede é então utilizada para prever o valor da cheia do ano $\mathrm{k}$ (ano excluído do conjunto de treinamento). A previsão final para o ano k é obtida calculando-se o valor médio das 25 previsões. No treinamento das redes o método bootstrap foi associado ao método de regularização $\mathrm{L}^{2}$ e ao método de parada antecipada, respectivamente. 
Os 25 conjuntos distintos de treinamento contêm, cada um, dados relativos a 100 anos. Como dispomos de apenas 67 anos (1951-2017) e sendo um deles retirado para se fazer a previsão (ano k), restam apenas 66 anos para o treinamento. Para se compor um conjunto de treinamento com dados relativos a 100 anos, os dados de alguns anos são repetidos de forma aleatória. A figura 2 ilustra o método bootstrap de treinamento da RNA.

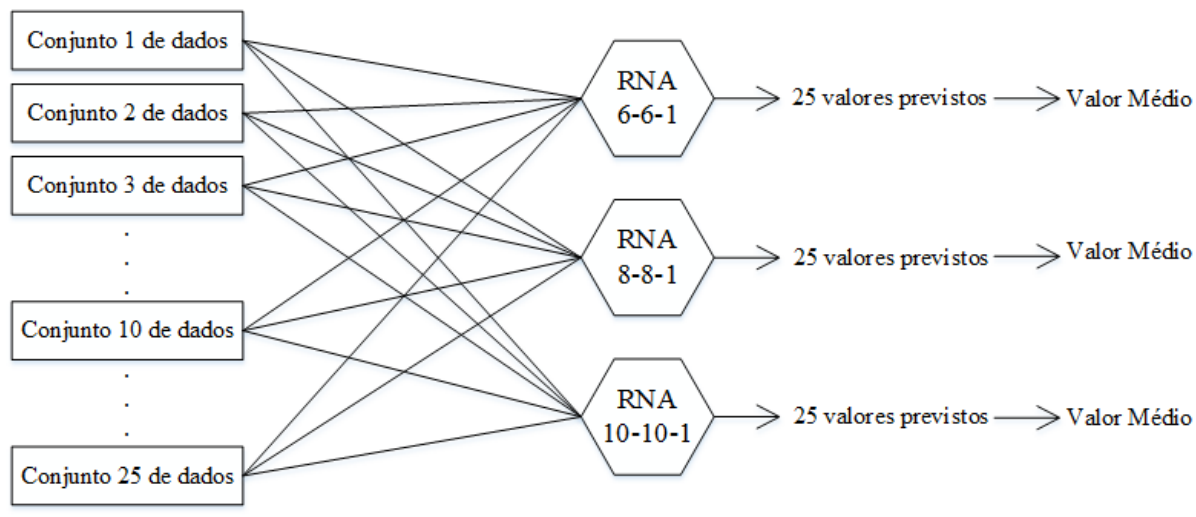

Figura 2. Método bootstrap de treinamento da RNA.

\subsection{Métodos de Bagging e Boosting}

Em aprendizado de máquina, tanto na classificação quanto na regressão, o conceito de comitê ou conjunto está associado a ideia de treinar-se múltiplos modelos utilizando o mesmo algoritmo. O objetivo é minimizar os erros devido a ruídos, polarização ou variância. Tanto no método de bagging quanto no de boosting, os diferentes conjuntos utilizados no treinamento dos modelos são produzidos por amostragem randômica, com reposição. No método bagging, qualquer padrão tem a mesma probabilidade de aparecer novamente em um novo conjunto de treinamento. Já no método boosting, os valores preditos erroneamente por um modelo anterior, têm maior probabilidade de aparecer novamente em um novo conjunto de treinamento. A ideia é que esse erro de predição possa ser corrigido. Árvores de decisão foram utilizadas com os métodos de bagging e boosting.

\subsection{Avaliação do Desempenho dos preditores}

\subsubsection{Coeficiente de Correlação de Pearson}

A primeira avaliação de desempenho dos preditores implementada foi através da utilização do coeficiente de correlação de Pearson, $r_{P}$, definido como o grau de associação entre duas variáveis aleatórias. Esse coeficiente é adimensional, com valores situados ente $-1,0$ e 1.0, e reflete a intensidade de uma relação linear entre dois conjuntos de dados (valores reais das cheias e valores preditos), com as seguintes condições: para $r_{P}=1$ significa uma correlação positiva perfeita entre duas variáveis; para $r_{P}=-1$ significa uma correlação negativa perfeita entre duas variáveis, isto é, se uma aumenta, a outra sempre diminui; para $r_{P}=0$ significa que as duas variáveis não dependem linearmente uma da outra. No entanto, pode existir uma outra dependência que seja "não linear". Assim, o resultado $r_{P}=0$ deve ser investigado por outros meios. 


\subsubsection{Faixas de classificação das cheias}

É proposto a classificação das cheias de acordo os critérios apresentados na Tabela 2, em quatro categorias, a saber: cheia baixa - faixa 1, cheia média baixa - faixa 2 , cheia média alta - faixa 3 e cheia alta - faixa 4. A discriminação dos valores de cota do rio para cada uma dessas faixas, baseou-se na consideração de que a distribuição dos picos de cheias do período de 1903 a 2017 assemelha-se a uma curva normal, cujo valor médio é M e o desvio padrão $\sigma$. Uma cheia é considerada média se o seu valor de pico estiver entre $\mathrm{M} \pm \sigma$. Assim, 68,26\% das cheias são consideradas como cheias médias. Dentro da classe de cheia média foi criada duas subclasses: média baixa $(M-\sigma)$ e média alta $(M+\sigma)$. Por fim, se o pico da cheia for < $(M-\sigma)$ é considerada como baixa $(15,87 \%$ das cheias) e se for $>$ $(\mathrm{M}-\sigma)$ é considerada alta (15,87\% das cheias). Dessa forma, os valores de pico das faixas, apresentados na Tabela 2, são dinâmicos e mudam à medida em que novos registros de cheia estejam disponíveis, posto que mudarão os valores de $\mathrm{M}$ e $\sigma$. Para os registros de 1903 à 2017, o valor médio é $M=27,87 \mathrm{~m}$ e o desvio padrão é $\sigma=1,15 \mathrm{~m}$.

Tabela 2. Faixas e classe de cheias em função da média e desvio padrão dos picos de cheias no período de 1903 a $2017(M=27,87 \mathrm{~m}$ e $\sigma=1,15 \mathrm{~m})$

\begin{tabular}{cccc}
\hline Faixa & Critério de classificação & Valor & Classificação \\
\hline 1 & $\mathrm{PC}_{\mathrm{p}}<(\mathrm{M}-\sigma)$ & $\mathrm{PC}_{\mathrm{p}}<26,72 \mathrm{~m}$ & Baixa \\
2 & $(\mathrm{M}-\sigma)<\mathrm{PC}_{\mathrm{p}}<\mathrm{M}$ & $26,72 \mathrm{~m}<\mathrm{PC}_{\mathrm{p}}<27,87 \mathrm{~m}$ & Média Baixa \\
3 & $\mathrm{M}<\mathrm{PC}_{\mathrm{p}}<(\mathrm{M}+\sigma)$ & $27,87 \mathrm{~m} \mathrm{PC}_{\mathrm{p}}<29,02 \mathrm{~m}$ & Média Alta \\
4 & $\mathrm{PC}_{\mathrm{p}}>(\mathrm{M}+\sigma)$ & $\mathrm{PC}_{\mathrm{p}}>29,02 \mathrm{~m}$ & Alta \\
\hline \multicolumn{2}{c}{$\mathrm{PC}_{\mathrm{p}}$ : Pico da cheia previsto } &
\end{tabular}

\subsection{3 Índices de Erro}

A terceira maneira utilizada para avaliar o desempenho dos preditores foi através da utilização dos índices de erro propostos por Schongart et al. (2007). Os índices de erro, nomeados como Ind_1, Ind_2, Ind_3 e Ind_4, são descritos a seguir:

- Ind_1: número de previsões em que o valor absoluto da diferença entre o valor previsto e o real é inferior $0,5 \mathrm{~m}$;

- Ind_2: número de previsões em que o valor absoluto da diferença entre o valor previsto e o real situa-se entre $0,5 \mathrm{~m}$ e $1 \mathrm{~m}$;

- Ind_3: número de previsões em que o valor absoluto da diferença entre o valor previsto e o real é superior a $1 \mathrm{~m}$ e inferior a1,5m;

- Ind_4: número de previsões em que o valor absoluto da diferença entre o valor previsto e o real é superior a $1,5 \mathrm{~m}$.

\section{Resultados}

Os algoritmos foram implementados utilizando o software Matlab R2018a. As diferenças entre os resultados obtidos com as diversas arquiteturas e métodos de generalização foram avaliadas através do teste de significância qui-quadrado $\left(\chi^{2}\right)$.

\subsection{Resultados das Redes Neurais Artificiais}

Foram realizadas várias simulações com o objetivo de determinar qual associação de conjunto de variáveis de entrada $[1,2,3,4,5,6,7,8$ e 9], arquitetura e método de generalização apresentam o melhor desempenho. 
Na Tabela 3 são apresentados os valores obtidos para o coeficiente de Pearson e para os índices de erro, para as três arquiteturas de redes neurais, em função do número de variáveis de entrada, métodos de generalização e antecedência da previsão. Observase que os melhores resultados são obtidos ao utilizar-se RNA com o método de generalização de parada antecipada, com 8 variáveis de entrada, arquitetura 10-10-1 e quando se realizou a previsão da cheia com 1 mês de antecedência do pico máximo, isto é, no mês de maio. O coeficiente de correlação de Pearson, para essa situação, foi de $r_{p}=0,9592$. Verifica-se que $94,02 \%$ dos anos, a previsão possui um erro absoluto inferior a $0,5 \mathrm{~m}$ e em $100 \%$ dos anos a previsão resultou em um erro absoluto menor que $1,5 \mathrm{~m}$.

Tabela 3. Resultados das simulações com 8 e 9 variáveis de entrada para as RNAs.

\begin{tabular}{|c|c|c|c|c|c|c|c|c|c|c|c|}
\hline \multirow{2}{*}{$\begin{array}{c}\text { N. de } \\
\text { variáveis }\end{array}$} & \multirow{2}{*}{ Arquit. } & \multicolumn{5}{|c|}{ Regularização $L^{2}+$ Boostrap } & \multicolumn{5}{|c|}{ Parada Antecipada + Bootstrap } \\
\hline & & $r_{p}$ & Ind_1 & Ind_2 & Ind_3 & Ind_4 & $\boldsymbol{r}_{p}$ & Ind_1 & Ind_2 & Ind_3 & Ind_4 \\
\hline \multicolumn{12}{|c|}{4 meses de antecedência } \\
\hline \multirow{3}{*}{8} & $6 \times 6 \times 1$ & 0,6428 & 28 & 24 & 13 & 2 & 0,6632 & 27 & 30 & 9 & 1 \\
\hline & $8 \times 8 \times 1$ & 0,6879 & 39 & 17 & 7 & 4 & 0,7309 & 36 & 26 & 4 & 1 \\
\hline & $10 \times 10 \times 1$ & 0,6768 & 33 & 23 & 8 & 3 & 0,6942 & 27 & 34 & 5 & 1 \\
\hline \multirow{3}{*}{9} & $6 \times 6 \times 1$ & 0,719 & 32 & 26 & 7 & 2 & 0,6857 & 33 & 24 & 9 & 1 \\
\hline & $8 \times 8 \times 1$ & 0,6708 & 31 & 25 & 9 & 2 & 0,7171 & 34 & 23 & 9 & 1 \\
\hline & $10 \times 10 \times 1$ & 0,5936 & 32 & 19 & 12 & 4 & 0,6953 & 34 & 22 & 10 & 1 \\
\hline \multicolumn{12}{|c|}{3 meses de antecedência } \\
\hline \multirow{3}{*}{8} & $6 \times 6 \times 1$ & 0,7439 & 35 & 26 & 4 & 2 & 0,7983 & 35 & 28 & 3 & 1 \\
\hline & 8x8x1 & 0,71 & 36 & 21 & 9 & 1 & 0,7977 & 38 & 24 & 3 & 2 \\
\hline & $10 \times 10 \times 1$ & 0,7135 & 36 & 20 & 9 & 2 & 0,7964 & 34 & 27 & 5 & 1 \\
\hline \multirow{3}{*}{9} & $6 \times 6 \times 1$ & 0,8048 & 39 & 19 & 9 & 0 & 0,8036 & 39 & 22 & 6 & 0 \\
\hline & $8 \times 8 \times 1$ & 0,7762 & 33 & 28 & 5 & 1 & 0,7944 & 37 & 24 & 6 & 0 \\
\hline & $10 \times 10 \times 1$ & 0,8187 & 41 & 20 & 5 & 1 & 0,8203 & 42 & 20 & 3 & 2 \\
\hline \multicolumn{12}{|c|}{2 meses de antecedência } \\
\hline \multirow{3}{*}{8} & $6 \times 6 \times 1$ & 0,8859 & 45 & 19 & 3 & 0 & 0,9238 & 55 & 11 & 1 & 0 \\
\hline & $8 \times 8 x 1$ & 0,8421 & 43 & 21 & 2 & 1 & 0,8938 & 51 & 14 & 1 & 1 \\
\hline & $10 \times 10 \times 1$ & 0,8668 & 48 & 16 & 2 & 1 & 0,903 & 45 & 21 & 1 & 0 \\
\hline \multirow{3}{*}{9} & $6 \times 6 \times 1$ & 0,7772 & 39 & 22 & 3 & 3 & 0,8954 & 49 & 16 & 2 & 0 \\
\hline & $8 x 8 x 1$ & 0,7937 & 38 & 22 & 5 & 2 & 0,9087 & 52 & 14 & 1 & 0 \\
\hline & $10 \times 10 \times 1$ & 0,8664 & 42 & 23 & 2 & 0 & 0,8992 & 53 & 11 & 3 & 0 \\
\hline \multicolumn{12}{|c|}{1 mês de antecedência } \\
\hline \multirow{3}{*}{8} & $6 \times 6 \times 1$ & 0,9127 & 52 & 14 & 1 & 0 & 0,9556 & 64 & 2 & 1 & 0 \\
\hline & $8 \times 8 x 1$ & 0,9223 & 51 & 16 & 0 & 0 & 0,958 & 63 & 4 & 0 & 0 \\
\hline & $10 \times 10 \times 1$ & 0,9457 & 60 & 7 & 0 & 0 & 0,9592 & 63 & 4 & 0 & 0 \\
\hline \multirow{3}{*}{9} & $6 \times 6 \times 1$ & 0,9081 & 51 & 15 & 1 & 0 & 0,9565 & 61 & 6 & 0 & 0 \\
\hline & $8 \times 8 x 1$ & 0,9163 & 49 & 18 & 0 & 0 & 0,949 & 59 & 8 & 0 & 0 \\
\hline & 10x10x1 & 0,9274 & 55 & 10 & 2 & 0 & 0,9486 & 58 & 8 & 1 & 0 \\
\hline
\end{tabular}

$\mathrm{Na}$ Tabela 4 é apresentada a matriz de confusão para a classificação em faixas, utilizando-se os melhores preditores apresentados na Tabela 3, segundo o coeficiente de Pearson, para os dois métodos de generalização. A partir da Tabela 4, observa-se que, para o método de regularização, houve 49 acertos (elementos na diagonal principal) e 17 erros. Já, para o método de parada antecipada, houve 57 acertos e 10 erros. Assim, obtémse uma acurácia de 74,62 \% para o método de regularização $\mathrm{L}^{2}$ e uma acurácia de $85,07 \%$ para o método de parada antecipada.

Para avaliar o desempenho das RNAs com os métodos de generalização (regularização $\mathrm{L}^{2}$ e parada antecipada), aplicou-se o teste $\chi^{2}$ (qui-quadrado) aos valores obtidos na Tabela 4, considerando o número de acertos e erros de cada método. Assim, o teste é aplicado a uma tabela de contingência com 2 colunas por 2 linhas, ou seja, com um grau de liberdade, $g l=1$. O nível de significância adotado foi de 95\%, com um valor 
crítico, $t_{c}=3,84$. A hipótese nula é que não existe diferenças significativas entre os valores de acertos e erros obtidos com o método de regularização $\mathrm{L}^{2} \mathrm{e}$ de parada antecipada. $\mathrm{O}$ valor obtido de $\chi^{2}=5,11$. Como $\chi^{2}>t_{c}$, a hipótese nula deve ser rejeitada, ou seja, existe diferença estatisticamente significante entre o número de acertos e erros de ambos os métodos. Assim, o método de parada antecipada é superior ao método de regularização $\mathrm{L}^{2}$.

Tabela 4. Matriz de confusão para a classificação em faixas usando RNA.

\begin{tabular}{|c|c|c|c|c|c|c|c|c|c|}
\hline & \multirow[b]{3}{*}{ Faixas } & \multicolumn{4}{|c|}{ Regularização + Bootstrap } & \multicolumn{4}{|c|}{ Parada Antecipada+ Bootstrap } \\
\hline & & \multicolumn{4}{|c|}{ Valores previstos } & \multicolumn{4}{|c|}{ Valores previstos } \\
\hline & & 1 & 2 & 3 & 4 & 1 & 2 & 3 & 4 \\
\hline \multirow{4}{*}{ 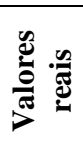 } & 1 & 3 & 4 & 0 & 0 & 4 & 3 & 0 & 0 \\
\hline & 2 & 0 & 13 & 3 & 0 & 0 & 15 & 1 & 0 \\
\hline & 3 & 0 & 3 & 27 & 2 & 0 & 2 & 29 & 1 \\
\hline & 4 & 0 & 0 & 5 & 7 & 0 & 0 & 3 & 9 \\
\hline
\end{tabular}

\subsection{Resultados das Árvores de Decisão com Aprendizado Baseado em Comitê}

Na Tabela 5 são apresentados os valores dos coeficientes de Pearson e dos índices de erro, para os métodos de bagging e boosting, em função do número de variáveis de entrada. Observa-se que os melhores resultados foram obtidos utilizando o método de bagging, apresentando $r_{p}=0,9374$. Esse valor foi obtido utilizando 8 variáveis de entrada, selecionadas pelo método de seleção escalar de características modificado, a previsão da cheia foi realizada com 1 mês de antecedência do pico máximo, isto é, no mês de maio. Os resultados mostram que em $85,07 \%$ dos anos a previsão possui um erro menor do que 0,5m; em 98,51\% dos anos a previsão resultou em um erro menor do que $1 \mathrm{~m}$; e em $100 \%$ dos anos a previsão resultou em um erro menor do que $1,5 \mathrm{~m}$.

Tabela 5. Resultados das simulações para os métodos de Aprendizado usando árvores de decisão e aprendizado baseado em comitê.

\begin{tabular}{|c|c|c|c|c|c|c|c|c|c|c|c|}
\hline \multirow{2}{*}{$\begin{array}{c}\text { N. de } \\
\text { variáveis }\end{array}$} & \multicolumn{5}{|c|}{ Bagging } & \multirow{2}{*}{$\begin{array}{c}\text { N. de } \\
\text { variáveis }\end{array}$} & \multicolumn{5}{|c|}{ Boosting } \\
\hline & $r_{p}$ & Ind_1 & Ind_2 & Ind_3 & Ind_4 & & $r_{p}$ & Ind_1 & Ind_2 & Ind_3 & Ind_4 \\
\hline \multicolumn{12}{|c|}{4 meses de antecedência } \\
\hline 1 & 0,7091 & 31 & 26 & 9 & 1 & 1 & 0,6158 & 22 & 30 & 11 & 4 \\
\hline 6 & 0,7145 & 30 & 30 & 6 & 1 & 2 & 0,6751 & 30 & 23 & 9 & 5 \\
\hline \multicolumn{12}{|c|}{3 meses de antecedência } \\
\hline 1 & 0,8583 & 45 & 20 & 2 & 0 & 1 & 0,8089 & 35 & 24 & 8 & 0 \\
\hline 6 & 0,8309 & 36 & 27 & 3 & 1 & 7 & 0,8172 & 38 & 24 & 4 & 1 \\
\hline \multicolumn{12}{|c|}{2 meses de antecedência } \\
\hline 1 & 0,9077 & 49 & 17 & 1 & 0 & 4 & 0,904 & 48 & 18 & 1 & 0 \\
\hline 4 & 0,9029 & 49 & 16 & 2 & 0 & 5 & 0,9012 & 50 & 16 & 1 & 0 \\
\hline \multicolumn{12}{|c|}{1 mês de antecedência } \\
\hline 8 & 0,9374 & 57 & 9 & 1 & 0 & 8 & 0,9154 & 52 & 14 & 1 & 0 \\
\hline 9 & 0,9353 & 57 & 9 & 1 & 0 & 9 & 0,9074 & 50 & 17 & 0 & 0 \\
\hline
\end{tabular}

Na Tabela 6 é apresentada a matriz de confusão para a classificação em faixas, utilizando-se os melhores preditores apresentados na Tabela 5, segundo o coeficiente de Pearson, para os métodos boosting e bagging. A partir da Tabela 6, obtém-se uma acurácia de $82,09 \%$ para o método de bagging e uma acurácia de $74,63 \%$ para o método de boosting. Aplicando o teste $\chi^{2}$ aos dados da Tabela 6 , nas mesmas condições em que o mesmo foi aplicado à Tabela 4 , calculamos o valor de $\chi^{2}=3,97$. Assim, como $\chi^{2}>$ $t_{c}$, a hipótese nula deve ser rejeitada, ou seja, existe diferença estatisticamente 
significante entre o número de acertos e erros de ambos os métodos. Assim, o método de bagging é superior ao método de boosting, com árvore de decisão.

Tabela 6. Matriz de confusão para a classificação em faixas usando Árvores de Decisão com aprendizado baseado em comitê.

\begin{tabular}{|c|c|c|c|c|c|c|c|c|c|}
\hline & \multirow[b]{3}{*}{ Faixas } & \multicolumn{4}{|c|}{ Bagging } & \multicolumn{4}{|c|}{ Boosting } \\
\hline & & \multicolumn{4}{|c|}{ Valores previstos } & \multicolumn{4}{|c|}{ Valores previstos } \\
\hline & & 1 & 2 & 3 & 4 & 1 & 2 & 3 & 4 \\
\hline \multirow{4}{*}{ 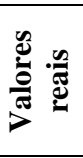 } & 1 & 5 & 2 & 0 & 0 & 4 & 3 & 0 & 0 \\
\hline & 2 & 1 & 13 & 2 & 0 & 2 & 10 & 4 & 0 \\
\hline & 3 & 0 & 2 & 27 & 3 & 0 & 1 & 26 & 5 \\
\hline & 4 & 0 & 0 & 2 & 10 & 0 & 0 & 2 & 10 \\
\hline
\end{tabular}

\section{Discussão e Conclusão}

Inicialmente, destaca-se duas contribuições importantes deste trabalho. A primeira foi a previsão de cheias sazonais do rio Negro com antecedência de um a quatro meses em relação a ocorrência do pico da cheia, utilizando Redes Neurais Artificiais e Árvores de Decisão, com aprendizado baseado em comitê. Em trabalhos anteriores (Rodrigues et al. [2005] e Schongart et al. [2007]), essa previsão era feita com apenas 4 meses de antecedência. A segunda foi a classificação das cheias em faixas, através de uma metodologia de enquadramento que considera a média e o desvio padrão dos picos das cheias ocorridas num dado período (neste caso, de 1903 a 2017). Esse enquadramento em faixas possibilita uma nova avaliação do desempenho dos preditores através de matrizes de confusão e permite aos órgãos públicos anunciarem as previsões das cheias de forma mais intuitiva, do que simplesmente anunciando números.

A partir dos resultados apresentados anteriormente, conclui-se que os melhores resultados deste trabalho foram obtidos utilizando-se RNA com o método de generalização de parada antecipada. No entanto, ao se aplicar o teste de $\chi^{2}$ aos resultados obtidos nas Tabelas 4 e 6, com os métodos de parada antecipada e bagging com árvores de decisão, respectivamente, obteve-se um valor de $\chi^{2}=2,03$. Assim, como $\chi^{2}<t_{c}$, a hipótese nula deve ser aceita, ou seja, não existe diferença estatisticamente significante entre o número de acertos e erros de ambos os métodos. Assim, o método de parada antecipada não é superior ao método de bagging com árvores de decisão.

A Tabela 7 apresenta uma comparação entre os três Índices de Erro dos melhores resultados obtidos nesse trabalho utilizando RNA e máquina de comitê, com o melhor resultado obtido por Rodrigues et. al. [2015], considerando 4 meses de antecedência. Observa-se que os percentuais de acerto foram levemente superiores àqueles obtidos por Rodrigues et al. [2015].

Uma característica importante da metodologia empregada é que a mesma faz uso de comitês de preditores, o que confere maior credibilidade aos resultados obtidos.

Uma limitação no desenvolvimento do trabalho é que os dados disponíveis para treinamento, validação e teste dos preditores são bem limitados, referindo-se apenas a um período de 67 anos, que vai de 1903 a 2017. Face a essa limitação, objetivando maximizar o conjunto de treinamento, utilizamos o método leave-one-out para o treinamento e teste dos preditores. Nesse contexto, as redes neurais artificiais tiveram um desempenho superior às arvores de decisão. 
Tabela 7. Comparação de desempenho entre o preditor RNA deste trabalho e o implementado por Rodrigues et.al. (2015) para previsão de cheias com 4 meses de antecedência.

\begin{tabular}{lccc}
\hline \multicolumn{1}{c}{ Erro } & $\begin{array}{c}\text { RNA implementada por } \\
\text { Rodrigues et.al. (2015) }\end{array}$ & *RNA & $\begin{array}{c}\text { *Máquina } \\
\text { Comitê }\end{array}$ \\
\hline Ind_1 [erro $\leq 0,5 \mathrm{~m}]$ & $51,56 \%$ & $53,73 \%$ & $44,77 \%$ \\
Ind_1 + Ind_2 [erro $\leq 1 \mathrm{~m}]$ & $92,18 \%$ & $92,53 \%$ & $89,55 \%$ \\
Ind_1 + Ind_2 + Ind_3 & $98,43 \%$ & $98,51 \%$ & $98,51 \%$ \\
*erro $\leq 1,5 \mathrm{~m}]$ & &
\end{tabular}

Embora esse trabalho dedique-se a previsão de cheias, a abordagem utilizada não fez uso de séries temporais. O treinamento de ambos os métodos empregados, redes neurais e árvores de decisão, fez uso de técnicas supervisionadas, com pares entrada saída [9,1], sendo as 9 variáveis apresentadas paralelamente à entrada da rede, para a previsão do nível da cheia do ano a que as mesmas se referem. Em trabalhos futuros pretende-se utilizar uma abordagem sequencial de entrada de informações nos preditores, através da utilização de redes recorrentes, uni e bidirecionais, e comparar os resultados das predições das cheias com aqueles ora obtidos.

\section{Agradecimentos}

Essa pesquisa foi suportada pela Samsung Eletrônica da Amazônia Ltda, sob os termos da Lei Federal 8.387/91, através de convênio firmado com o CETELI/UFAM.

\section{Referências}

Climate Prediction Center. [2018]. "NOAA Center for Weather and Climate Prediction". Climate Prediction Center. [Online] 2018. [Citado em: 14 de Junho de 2018.] $\mathrm{ftp} / / / \mathrm{ftp} . c p c . n c e p . n o a a . g o v / w d 52 \mathrm{dg} / \mathrm{data} /$ indices/sstoi.indices.

Córdoba-Machado, Samir, et. al. [2016]. "Seasonal streamflow prediction in Colombia using atmospheric and oceanic patterns". Journal of Hydrology. 2016, Vol. 538.

Matsunaga, Victoria Yukie. [2012]. "Curso de Redes Neurais Utilizando o Matlab". Belém - Pará : s.n., 2012.

MMA [2007] “Atlas das Áreas Susceptíveis à Desertificação do Brasil”, Brasília.

Porto de Manaus. [2018]. [Online] 2018. [Citado em: 13 de Julho de 2018.] https://www.portodemanaus.com.br/?pagina=niveis-maximo-minimo-do-rio-negro.

Rodrigues, Márcio M., Costa, Marly G. F. e Filho, Cícero F. F. C. [2015]. "Proposta de um Método para Previsão de Cheias Sazonais Utilizando Redes Neurais Artificiais: Uma Aplicação ao Rio Amazonas”. Google Scholar. 2015.

Schongart, Jochen e Junk, Wolfgang J. [2007]. "Forecasting the flood-pulse in Central Amazonia by ENSO-indices”. Journal of Hydrology. 335, 2007.

Sonka, Milan e Fitzpatrick, J. Michael. [2000]. "Medical Image Processing and Analysis". Washington : Spie Press, 2000.

Zhou, Zhi-Hua. [2012]. "Ensemble Methods: Foundations and Algoritms". Boca Raton: CRC Press, 2012. 978-1-4398-3005-5. 